\title{
A Temperature-Sensitive Paralytic Mutant Defines a Primary Synaptic Calcium Channel in Drosophila
}

\author{
Fumiko Kawasaki, Ryan Felling, and Richard W. Ordway \\ Department of Biology, The Pennsylvania State University, University Park, Pennsylvania 16802
}

Neurotransmission at chemical synapses involves regulated exocytosis of neurotransmitter from the presynaptic terminal. Neurotransmitter release is thought to be triggered by calcium influx through specific classes of voltage-gated calcium channels. Here we report genetic and functional analysis implicating a specific calcium channel gene product in neurotransmitter release. We have isolated a temperature-sensitive paralytic allele of the Drosophila calcium channel $\alpha 1$ subunit gene, cacophony (cac). This mutant, referred to as $\mathrm{cac}^{\mathrm{TS} 2}$, allows functional analysis of synaptic transmission after acute perturbation of a specific $\alpha 1$ subunit. Electrophysiological analysis at neuromuscular synapses revealed that neurotransmitter release in $\mathrm{cac}^{\mathrm{TS} 2}$ is markedly reduced at elevated temperatures, indicating that cac encodes a primary $\alpha 1$ subunit functioning in synaptic transmission. These observations further define the molecular basis of voltage-gated calcium entry at synapses and provide a new starting point for further genetic analysis of synaptic mechanisms.

Key words: calcium channel; neurotransmitter release; synaptic transmission; cacophony; Drosophila; temperature-sensitive
A number of studies have implicated specific classes of voltagegated calcium channels in neurotransmitter release (for review, see Wheeler et al., 1995; Catterall, 1998). These channels are composed of multiple subunits, including $\alpha 1$, the primary structural subunit, as well as $\alpha 2 \delta, \beta$, and $\gamma$ subunits. $\alpha 1$ subunits of the $\mathrm{A}$ and $\mathrm{B}$ classes have been localized to synaptic terminals (Robitaille et al., 1990; Westenbroek et al., 1995), and heterologous expression shows that their pharmacology resembles that of calcium channels involved in neurotransmitter release. Furthermore, these $\alpha 1$ subunits contain a defined synaptic protein interaction (SYNPRINT) domain that interacts directly with the neurotransmitter release apparatus and may participate in coupling calcium influx to fast synaptic vesicle fusion (Mochida et al., 1996; Rettig et al., 1997; Sheng et al., 1998). Our current understanding of calcium channel function in neurotransmitter release will be further enhanced by complementary genetic analysis defining the in vivo functions and interactions of specific calcium channel gene products. Here we report analysis of synaptic function in a temperature-sensitive (TS) calcium channel mutant of Drosophila.

To define the physiological roles of specific proteins in synaptic transmission, we have focused on Drosophila mutants exhibiting rapid TS paralysis. These mutants typically develop and function normally at permissive temperature and can be shifted to restrictive temperature to examine the acute functional consequences of perturbing a specific gene product. This approach was pioneered almost 30 years ago (Suzuki et al., 1971; Grigliatti et al., 1973; Siddiqi and Benzer, 1976), and one of the mutants recovered in these early screens was comatose (comt). Our previous work has

Received Jan. 21, 2000; revised April 12, 2000; accepted April 24, 2000.

This work was supported by National Science Foundation Grant IBN-9514485. We gratefully acknowledge several members of the lab, Bonnie Dellinger, Missy Hazen, and Kamal Tilakaratne for participating in aspects of this work. We thank Jeffrey C. Hall (Brandeis University) for providing several cac stocks and for stimulating discussions. Deficiency stocks were obtained from the Bloomington Stock Center.

Correspondence should be addressed to Richard W. Ordway, Department of Biology, 208 Mueller Laboratory, Penn State University, University Park, PA 16802. E-mail: rwo4@psu.edu.

Copyright (C) 2000 Society for Neuroscience $\quad 0270-6474 / 00 / 204885-05 \$ 15.00 / 0$ shown that the comt gene product, a homolog of the $N$-ethylmaleimide-sensitive fusion protein (Ordway et al., 1994; Pallanck et al., 1995), functions in priming synaptic vesicles for fast, calcium-triggered fusion (Kawasaki et al., 1998; Kawasaki and Ordway, 1999a,b). To broaden our analysis to other gene products functioning in synaptic vesicle trafficking, we performed a genetic screen to identify mutations exhibiting functional interactions with comt (Dellinger et al., 2000). One enhancer of comt was determined to be a TS allele of cacophony ( cac) and has been designated $\mathrm{cac}^{\mathrm{TS} 2}$. $\mathrm{cac}$ encodes a homolog of voltage-activated calcium channel $\alpha 1$ subunits implicated in neurotransmitter release (Smith et al., 1996).

The cac locus was first identified in a screen for mutants exhibiting altered courtship song (von Schilcher, 1976, 1977) and was subsequently found to be allelic to the nightblind $A(n b A)$ locus (Heisenberg and Götz, 1975; Smith et al., 1998). A synaptic function for $c a c$-encoded calcium channels was suggested by electroretinogram recordings from $c a c$ ( $n b A$ ) mutants (Heisenberg and Götz, 1975; Smith et al., 1998), by the similarity between cac and $\alpha 1$ subunits previously implicated in synaptic transmission (Smith et al., 1996), and by the genetic interaction of $\mathrm{cac}^{\mathrm{TS} 2}$ with comt (Dellinger et al., 2000). Here we report functional analysis demonstrating that cac encodes a primary $\alpha 1$ subunit functioning in neurotransmitter release.

Parts of this work have been reported previously in abstract form (Dellinger et al., 1999; Kawasaki et al., 1999).

\section{MATERIALS AND METHODS}

Drosophila lines. Previously isolated cac lines were generously provided by Jeffrey C. Hall (Brandeis University, Waltham, MA). The deficiency line $D f(1) K A 10$ was obtained from the Bloomington Stock Center (Indiana University, Bloomington, IN). The left and right limits of this deficiency are 11A01 and 11A07-08, respectively. Wild-type flies were Canton S. All lines used for electrophysiological recording were maintained at $20^{\circ} \mathrm{C}$.

Synaptic electrophysiology. For experiments at dorsal longitudinal flight muscle (DLM) neuromuscular synapses, dissection, temperature control, motor axon stimulation, and two-electrode voltage-clamp recordings of 
synaptic currents were performed as described previously (Kawasaki et al., 1998).

Recordings of intracoxal lateral levator muscle (ICLM) synaptic currents were obtained as follows. A fly was anesthetized with $\mathrm{CO}_{2}$, mounted ventral side up over a hole in an air tube, and secured with wax (Tackiwax Boekel Industries, Feasterville, PA). Air was delivered to the tracheal system using an aquarium pump. The preparation was submerged in recording solution maintained at $20^{\circ} \mathrm{C}$. A tungsten knife was used to remove the ventral thoracic cuticle and the coxal muscles, thereby exposing the thoracic ganglion of the CNS. To expose the ICLMs of the first pair of legs, the overlying cuticle was removed from each coxa. The first leg nerve exiting the thoracic ganglion was cut and pulled into a suction electrode for stimulation.

ICLM synaptic currents were recorded by discontinuous single electrode voltage clamp using an AxoClamp-2B amplifier (Axon Instruments, Foster City, CA). Deviations from the command potential did not exceed $5 \mathrm{mV}$. Glass recording microelectrodes were filled with $3 \mathrm{M} \mathrm{KCl}$. The recording solution consisted of (in $\mathrm{mM}$ ): $129 \mathrm{NaCl}, 2 \mathrm{KCl}, 4.0$ $\mathrm{MgCl}_{2}, 1.0 \mathrm{CaCl}_{2}, 5 \mathrm{HEPES}$, and 36 sucrose. The $\mathrm{pH}$ was adjusted to 7.0 using $\mathrm{NaOH}$. Stimulation of the first leg nerve was performed using a suction electrode driven by an S-900/S-910 stimulator (Dagan Instruments, Minneapolis, MN). Temperature control was achieved with a TC-202 temperature controller and PDMI microincubator (Medical Systems Corporation, Greenvale, NY).

All recordings at 33 or $36^{\circ} \mathrm{C}$ were obtained after 5-20 min of exposure to the recording temperature. Recordings at $38^{\circ} \mathrm{C}$ were obtained after 1-2 min at this temperature.

Data acquisition and analysis. Data were acquired on-line using a Power Macintosh computer (Apple Computers, Cupertino, CA), Pulse software (Heka Electronik, Lambrecht, Germany), and an ITC-16 laboratory interface (Instrutech Corporation, Great Neck, NY). Data were low-pass filtered at 5 or $10 \mathrm{kHz}$ and acquired at $30 \mathrm{kHz}$. Measurement of synaptic currents was performed using cursor measurements in the data analysis software package IGOR (Wavemetrics, Lake Oswego, OR). Microsoft (Seattle, WA) Excel was used for data tabulation, graphing, and statistical analysis. Data are reported as the mean \pm SEM. By the use of an unpaired Student's $t$ test, statistical significance was assigned to comparisons with $p \leq 0.05$

Sequence analysis. The cac $\alpha 1$ subunit sequence (U55776) was aligned to human $\alpha 1 \mathrm{~A}$ (U76666), rat $\alpha 1 \mathrm{~B}$ (M92905), and rat $\alpha 1 \mathrm{C}$ (M67516) sequences by the Clustal method, using the MegAlign feature of the Lasergene sequence analysis software package (DNAStar Inc., Madison, WI). BLAST sequence similarity searches of the Drosophila genome were performed using the National Center for Biotechnology Information (NCBI) Drosophila genome resources (http://www.ncbi.nlm.nih.gov/ PMGifs/Genomes/7227.html). Query nucleotide and protein sequences included those corresponding to the SYNPRINT domain of the above vertebrate $\alpha 1 \mathrm{~A}$ and $\alpha 1 \mathrm{~B}$ genes [defined as residues $718-963$ in $\alpha 1 \mathrm{~B}$ (Sheng et al., 1998)], as well as the analogous domain of $\alpha 1 \mathrm{C}$ [residues 753-893 (Wiser et al., 1999)].

\section{RESULTS}

\section{A temperature-sensitive synaptic phenotype in cac $^{\text {TS2 }}$}

Electrophysiological analysis was performed in wild-type and $c a c^{\text {TS2 }}$ flies to investigate whether $c a c$-encoded $\alpha$ l subunits function in synaptic transmission. Two-electrode voltage-clamp techniques were used to record synaptic currents at DLM neuromuscular synapses. This technique prevents activation of postsynaptic voltage-gated ion channels and thus records the current passing through ligand-gated neurotransmitter receptor channels. The $\operatorname{cac}^{\text {TS2 }}$ mutant showed a conditional and reversible electrophysiological phenotype (Fig. 1). At $20^{\circ} \mathrm{C}, \mathrm{cac}^{\mathrm{TS} 2}$ exhibited wild-type synaptic currents. In contrast, exposure to elevated temperatures produced a marked reduction in the amplitude of the synaptic current with respect to wild type. This phenotype was reversible, showing full recovery upon return to $20^{\circ} \mathrm{C}$. The extent of the synaptic current reduction was dependent on temperature (Fig. 2 ). With respect to wild type, the current amplitude was reduced to $61.5 \pm 10.4 \%(n=5)$ at $33^{\circ} \mathrm{C}, 30.1 \pm 5.2 \%(n=8)$ at $36^{\circ} \mathrm{C}$, and $16.6 \pm 3.2 \%(n=4)$ at $38^{\circ} \mathrm{C}$.

The above results indicate that $c a c$-encoded $\alpha 1$ subunits func-

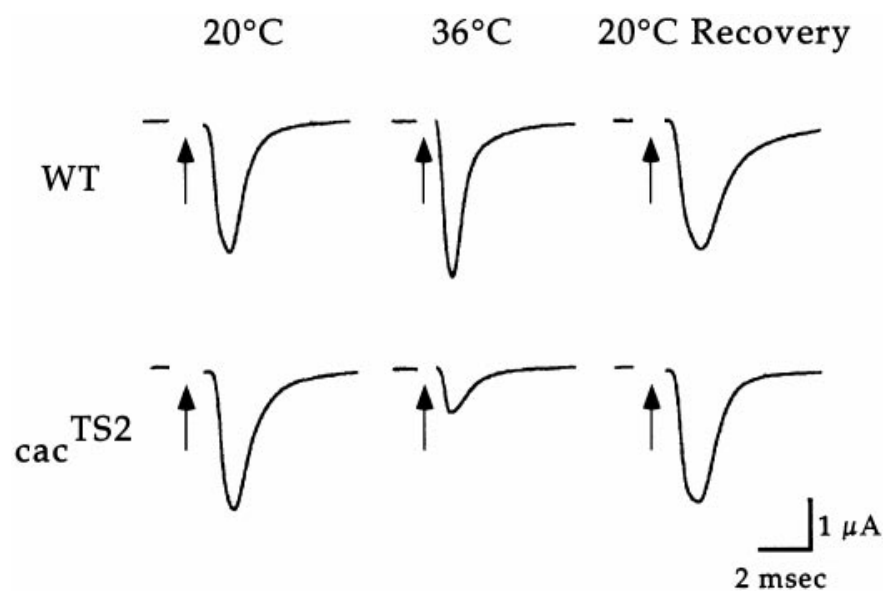

Figure 1. $\operatorname{cac}^{\mathrm{TS} 2}$ exhibits a conditional and reversible reduction in the synaptic current. DLM synaptic currents evoked by stimulation of the DLM motor axon were recorded at 20 and $36^{\circ} \mathrm{C}$, and at $20^{\circ} \mathrm{C}$ after exposure to $36^{\circ} \mathrm{C}\left(20^{\circ} \mathrm{C}\right.$ recovery $)$. The $20^{\circ} \mathrm{C}$ recovery traces in wild type and $\mathrm{cac}^{\mathrm{TS} 2}$ were recorded after 1 and $10 \mathrm{~min}$ at $20^{\circ} \mathrm{C}$, respectively. Axon stimulation is marked by the arrow. In each case, the $36^{\circ} \mathrm{C}$ and $20^{\circ} \mathrm{C}$ recovery traces were obtained from the same preparation.

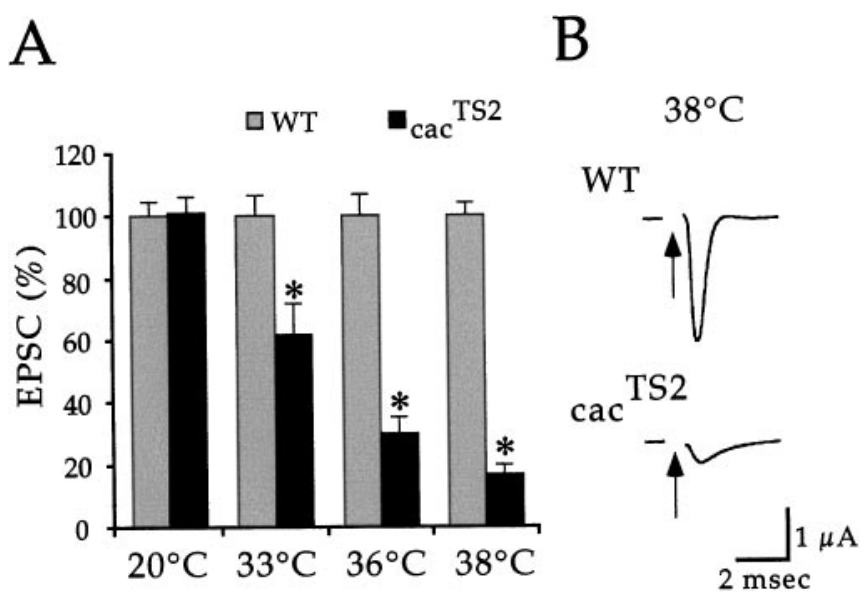

Figure 2. The extent of synaptic current reduction in $c a c^{\mathrm{TS} 2}$ is dependent on temperature. $A$, Peak amplitude measurements of DLM EPSCs from $c a c^{\mathrm{TS} 2}$ are shown as a mean percentage of wild-type currents. Error bars indicate SEM, and values significantly different from wild type are marked by an asterisk. $B$, Sample recordings from wild type and $\operatorname{cac}^{\mathrm{TS} 2}$ at $38^{\circ} \mathrm{C}$.

tion in synaptic transmission. Although our previous behavioral analysis shows that the $c a c^{\mathrm{TS} 2}, c a c^{\mathrm{s}}$, and $l(1) L 13$ mutations are allelic (Dellinger et al., 2000), we performed similar tests using electrophysiological analysis to confirm that the observed synaptic phenotype also maps to the $c a c$ locus. The recessive nature of $\mathrm{cac}^{\mathrm{TS} 2}$ was confirmed in recordings from heterozygous $c a c^{\mathrm{TS} 2} /+$ flies, which exhibit wild-type synaptic currents at restrictive temperature (Fig. $3 A$ ). In flies heterozygous for $c a c^{\mathrm{TS} 2}$ and a deficiency that removes $c a c$, the $c a c^{\text {TS2 }}$ phenotype was observed (Fig. $3 B)$. Finally, complementation tests were performed with other known $c a c$ alleles. A previously identified cac lethal mutation, l(1)L13, failed to complement the $\operatorname{cac}^{\mathrm{TS} 2}$ electrophysiological phenotype (Fig. $3 C$ ), indicating that this phenotype maps to the cac locus. This was further confirmed in recordings at $c a c^{\mathrm{TS} 2} / \mathrm{cac}^{\mathrm{S}}$ synapses as described below.

The above results show that a TS mutation in cac results in a 

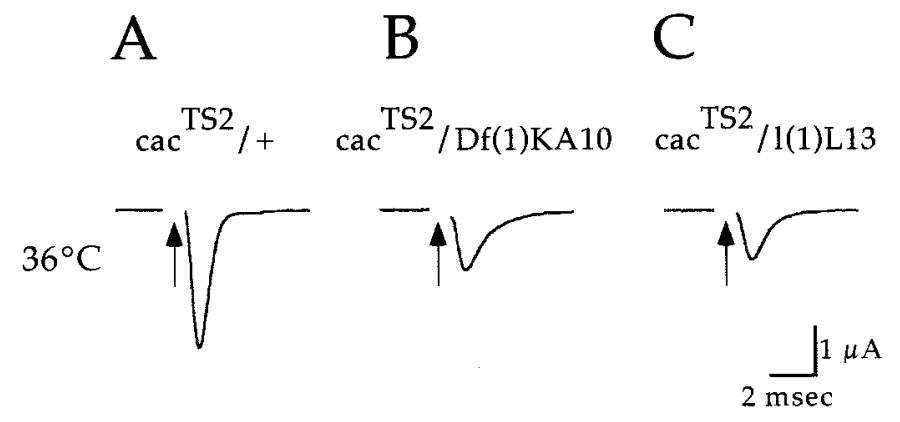

Figure 3. The synaptic current reduction observed in $\mathrm{cac}^{\mathrm{TS} 2}$ mutants maps to the cac locus. DLM synaptic current recordings in $c^{\mathrm{TS} 2} /+$ indicate a recessive $\mathrm{cac}^{\mathrm{TS} 2}$ synaptic phenotype $(A)$. Recordings from $\operatorname{cac}^{\mathrm{TS} 2} / D f(1) K A 10(B)$ and $\mathrm{cac}^{\mathrm{TS} 2} / 1(1) \mathrm{L} 13(C)$ map the observed synaptic phenotype to the $c a c$ locus.

conditional reduction in the synaptic current. We considered it likely that the $\mathrm{cac}^{\mathrm{TS} 2}$ phenotype was presynaptic on the basis that vertebrate homologs of $c a c$ have been implicated in neurotransmitter release and that our voltage-clamp analysis should prevent postsynaptic calcium channels from contributing to the recorded currents. To address this point directly, experiments were performed at neuromuscular synapses of the ICLM. This preparation is well suited for recording miniature EPSPs (mEPSPs). Because the amplitude of these mEPSPs reflects the postsynaptic response to a single quantum of neurotransmitter, mEPSPs may be used to monitor postsynaptic sensitivity to neurotransmitter. Voltage-clamp analysis of evoked ICLM synaptic currents confirmed that $c a c^{\mathrm{TS} 2}$ exhibits a conditional reduction in the synaptic current as observed at DLM synapses (Fig. 4A). Despite a marked reduction in the evoked synaptic current at $36^{\circ} \mathrm{C}, \mathrm{cac}^{\mathrm{TS} 2}$ synapses exhibited wild-type mEPSP amplitudes under the same conditions (Fig. $4 B$ ). Thus, we conclude that the $\mathrm{cac}^{\mathrm{TS} 2}$ phenotype is presynaptic, resulting from a conditional reduction in neurotransmitter release. In light of the striking reduction of the DLM synaptic current observed in $\mathrm{cac}^{\mathrm{TS} 2}$ at $38^{\circ} \mathrm{C}$ (Fig. 2), it appears that $c a c$ encodes the primary calcium channel $\alpha 1$ subunit responsible for neurotransmitter release at these synapses.

\section{An activity-dependent and temperature-independent synaptic phenotype in cac ${ }^{s}$}

Consistent with the $\mathrm{cac}^{\mathrm{TS} 2}$ phenotype, recordings from the original $c a c$ allele, $c a c^{\mathrm{s}}$, also showed reduced synaptic currents. However, unlike $c a c^{\mathrm{TS} 2}, c a c^{\mathrm{S}}$ exhibited a strictly activitydependent decrease in the synaptic current and no clear dependence on temperature (Fig. 5). Stimulation $(1 \mathrm{~Hz})$ at either $20^{\circ} \mathrm{C}$ or $36^{\circ} \mathrm{C}$ produced a wild-type synaptic current in response to the first stimulus, followed by reduced amplitude currents in response to subsequent stimuli. The distinct activity dependence of the $c a c^{\mathrm{S}}$ phenotype is illustrated by comparing $c a c^{\mathrm{S}}, c a c^{\mathrm{TS} 2}$, and wild-type synaptic currents during $1 \mathrm{~Hz}$ stimulation at $36^{\circ} \mathrm{C}$ (Fig. 5B).

As was the case for $c a c^{\mathrm{TS} 2}$, the $c a c^{\mathrm{S}}$ phenotype was observed in flies heterozygous for $c a c^{\mathrm{s}}$ and $D f(1) K A 10$ (data not shown). In addition, recordings obtained from $c a c$ s $/ c a c^{\mathrm{TS} 2}$ flies were informative. $\mathrm{cac}^{\mathrm{TS} 2}$ complemented the $\mathrm{cac}^{\mathrm{S}}$ phenotype at $20^{\circ} \mathrm{C}$ but failed to complement at $36^{\circ} \mathrm{C}$ (Fig. 6). These results further define the conditional phenotype of $c a c^{\mathrm{TS} 2}$ (see Discussion).

\section{DISCUSSION}

The availability of $c a c^{\mathrm{TS} 2}$, a calcium channel mutant exhibiting rapid temperature-sensitive paralysis, has provided a unique op-
A

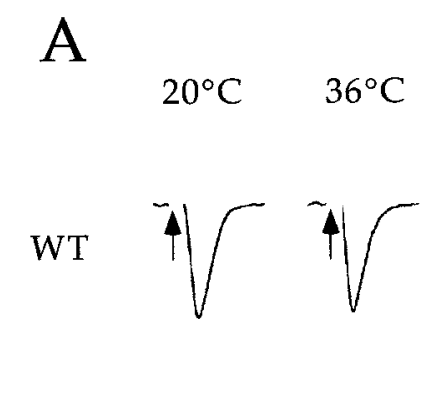

B
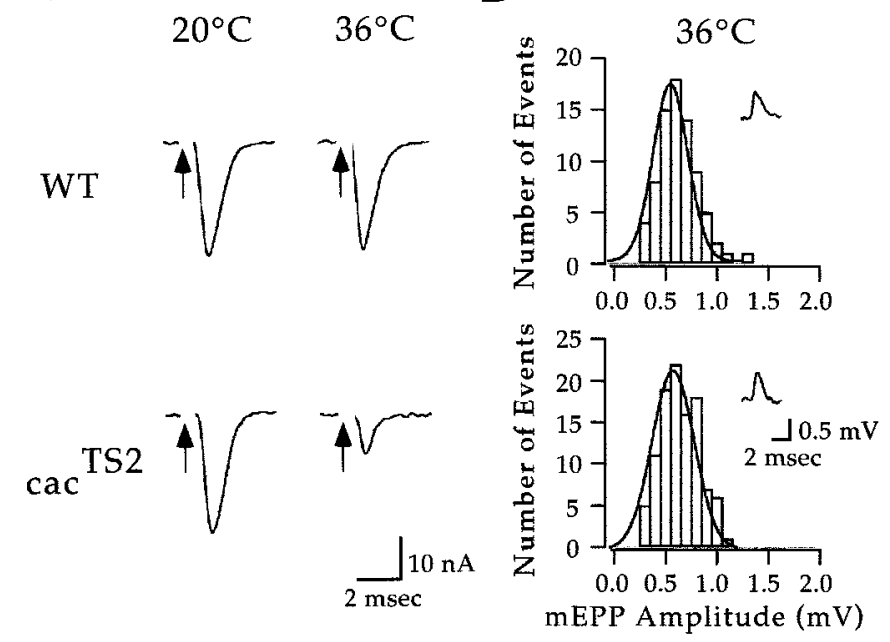

Figure 4. Recordings of spontaneous and evoked neurotransmitter release at ICLM synapses confirm a presynaptic role for cac-encoded $\alpha 1$ subunits in neurotransmitter release. $A$, Recordings of evoked synaptic currents from ICLM neuromuscular synapses in wild type (WT) and $\mathrm{cac}^{\mathrm{TS} 2}$. Similar results were obtained in three experiments for each genotype. $B$, Histograms of wild-type and $c a c^{\text {TS2 }}$ mEPSP amplitudes (mEPP Amplitude). The solid line represents a Gaussian fit to the data. Insets shown representative mEPSP recordings. Similar results were obtained in three experiments from each genotype.

portunity to examine the physiological role of a specific calcium channel gene product in synaptic transmission. Here we report genetic and functional analysis in two $c a c$ alleles, $c a c^{\mathrm{TS} 2}$ and $c a c^{\mathrm{s}}$, indicating that $c a c$ encodes a primary calcium channel $\alpha 1$ subunit functioning in neurotransmitter release.

\section{Behavior}

The present results provide further functional characterization of the $c a c$ locus, first identified in a screen for mutations affecting the male courtship song (von Schilcher, 1976, 1977). The courtship song is produced by a patterned beating of the wings, and this pattern, as well as the wing-beat amplitude, are altered in $c a c$ s mutants (von Schilcher, 1976, 1977; Smith et al., 1998). The results presented here suggest that impairment of neurotransmitter release at central synapses may contribute to altered song patterning in $c a c^{\mathrm{S}}$. Given that $c a c$-encoded $\alpha 1$ subunits function at flight muscle neuromuscular synapses, peripheral synaptic defects may influence the song phenotype as well.

$c a c$ also exhibits motor defects at elevated temperatures, including a lack of coordinated movement, spinning behavior, and ultimately paralysis after long exposures (Peixoto and Hall, 1998). Although the basis of this temperature-dependent behavior in $c a c^{\mathrm{s}}$ remains unclear, spontaneous neural activity generally increases at elevated temperatures (cf. Kawasaki and Ordway, 1999a) and thus may produce a more severe activity-dependent reduction in synaptic transmission.

\section{The cac $^{\text {s }}$ synaptic phenotype}

A distinctly activity-dependent and temperature-independent phenotype was observed at $c a c^{\mathrm{S}}$ synapses. The activitydependent reduction in the synaptic current is of interest in light of the molecular lesion identified in $c a c^{\mathrm{s}}$. The mutation maps to the sixth transmembrane segment of the third repeat (IIIS6), converting a highly conserved phenylalanine to an isoleucine (Smith et al., 1998). Because S6 segments have been implicated in 
A

B

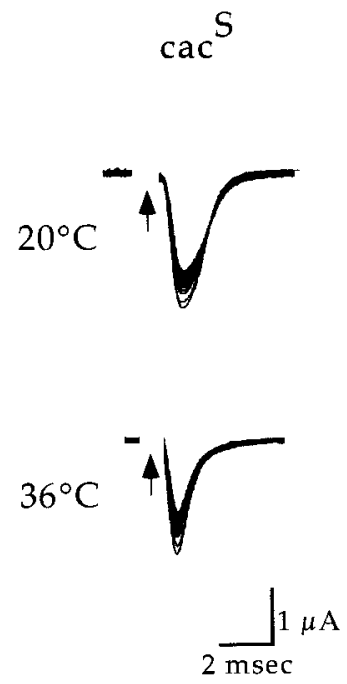

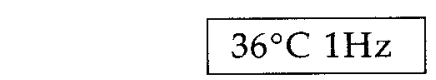

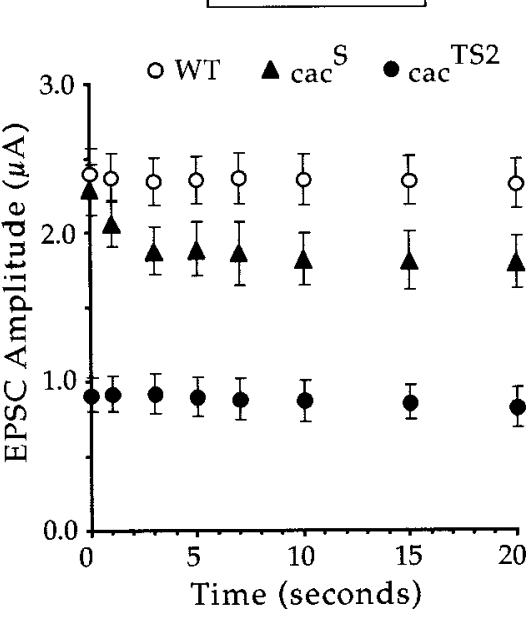

Figure 5. $\mathrm{cac}^{\mathrm{s}}$ exhibits an activity-dependent reduction in the synaptic current. $A$, Sample DLM synaptic currents from $c a c$ in response to $1 \mathrm{~Hz}$ stimulation at 20 and $36^{\circ} \mathrm{C}$. In each case, the first 50 traces were superimposed. Note the activity-dependent reduction in the synaptic current at both temperatures. $B$, Peak amplitude measurements of DLM EPSCs from wild type $(W T), c a c^{\mathrm{S}}$, and $c a c^{\mathrm{TS} 2}$ are plotted as a function of time during $1 \mathrm{~Hz}$ stimulation trains at $36^{\circ} \mathrm{C}$. Each point represents the mean \pm SEM for four experiments in $c a c^{\mathrm{S}}$ and $c a c^{\mathrm{TS} 2}$ and seven experiments in wild type.

fast inactivation of calcium (Zhang et al., 1994; Hering et al., 1998), sodium (Rojas et al., 1991; McPhee et al., 1995; Cannon, 1996), and potassium (Hoshi et al., 1991) channels, these results raise the possibility that altered inactivation contributes to the activity dependence of the $c a c^{\mathrm{S}}$ phenotype. Heterologous expression of wild-type and mutant forms of the cac gene, followed by analysis of the resulting calcium currents, is expected to further address this issue. Similarly, molecular characterization of $\mathrm{cac}^{\text {TS2 }}$ is expected to reveal the structural basis of the TS phenotype in this mutant.

\section{Heteroallelic interactions of cac $^{\text {TS2 }}$ and $c a c^{\mathrm{s}}$}

In $c a c^{\mathrm{TS} 2} / c a c^{\mathrm{S}}$ flies, $c a c^{\mathrm{TS} 2}$ complements the activity-dependent synaptic phenotype of $\mathrm{cac}^{\mathrm{S}}$ at $20^{\circ} \mathrm{C}$. However, shifting the temperature to $36^{\circ} \mathrm{C}$ does not produce a reduction in the synaptic current as observed in $\mathrm{cac}^{\mathrm{TS} 2}$ but rather reveals the activitydependent current reduction characteristic of $\mathrm{cac}^{\mathrm{S}}$ channels. Thus, it appears that the population of $\alpha 1$ subunits mediating fusion of a synaptic vesicle may contain a mixture of $c a c^{\mathrm{TS} 2}$ and $c a c^{\mathrm{S}}$ subunits and that each subpopulation can support a wildtype level of neurotransmitter release. These observations suggest substantial redundancy in calcium channel function at sites of synaptic vesicle fusion.

\section{cac-encoded $\alpha 1$ subunits lack homology to defined SYNPRINT domains}

The cac amino acid sequence is most closely related to the vertebrate $\alpha 1 \mathrm{~A}$ and $\alpha 1 \mathrm{~B}$ subunits (Smith et al., 1996), which contain a SYNPRINT domain within the second intracellular loop. However, alignments of these sequences (see Materials and Methods) indicate that this SYNPRINT domain is absent from the $c a c \alpha 1$ subunit, producing a gap at this position in the $c a c$ sequence. Similar results were obtained in alignments of $c a c$ with

$$
\operatorname{cac}^{\mathrm{TS} 2} / \mathrm{cac}^{\mathrm{S}}
$$
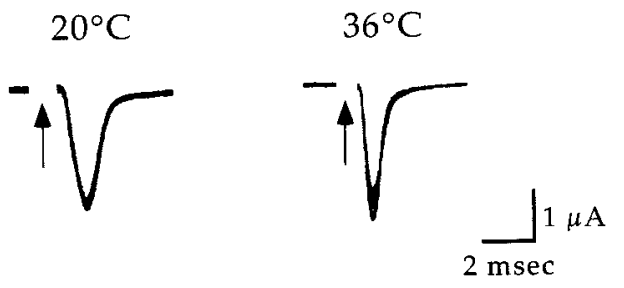

Figure 6. Heteroallelic interactions of $c a c^{\mathrm{TS} 2}$ and $c a c^{\mathrm{S}}$. DLM synaptic current recordings at $c a c^{\mathrm{TS} 2} / \mathrm{cac}^{\mathrm{S}}$ synapses. The cut DLM motor axon was stimulated at $1 \mathrm{~Hz}$, and in each case, the first 50 traces were superimposed. Similar results were obtained in four experiments.

the rat $\alpha 1 \mathrm{C}$ subunit, which contains a different synaptic protein binding domain at this position (Wiser et al., 1999). The above results are consistent with BLAST queries of the Drosophila genome (Adams et al., 2000) using either of the above synaptic protein binding sequences (see Materials and Methods), which reveal no homologous domains. Given the primary role of the $c a c$ gene product in neurotransmitter release, the absence of a conserved synaptic protein binding sequence suggests either a novel interaction domain or an alternative mechanism for fast coupling of calcium influx to synaptic vesicle fusion.

The importance of synaptic calcium channels is reflected by the in vivo consequences of their genetic disruption. In addition to the synaptic and behavioral phenotypes observed in cac mutants, mutations in homologous $\alpha 1$ subunit genes give rise to several genetic disorders in humans and mice (Hess, 1996; Miller, 1997). Thus, synaptic calcium channels play important roles in behavior, synaptic transmission, and human disease. The results presented here further define the molecular mechanisms of voltage-gated calcium entry at synapses and a provide a new starting point for genetic analysis of synaptic mechanisms in this model system (Brooks et al., 2000).

\section{REFERENCES}

Adams MD, Celniker SE, Holt RA, Evans CA, Gocayne JD, Amanatides PG, Scherer SE, Li PW, Hoskins RA, Galle RF, et al. (2000) The genome sequence of Drosophila melanogaster. Science 287:2185-2195. Brooks IM, Felling R, Ordway RW (2000) Genetic modifiers of cacTS2, a temperature-sensitive paralytic calcium channel mutant of Drosophila. Abstract presented at the meeting of the 41th Annual Drosophila Research Conference, Pittsburgh, PA.

Cannon SC (1996) Sodium channel defects in mytonia and periodic paralysis. Annu Rev Neurosci 19:141-164.

Catterall WA (1998) Structure and function of neuronal $\mathrm{Ca}^{2+}$ channels and their role in neurotransmitter release. Cell Calcium 24:307-323.

Dellinger BB, Felling R, McKinney C, Kawasaki F, Ordway RW (1999) Temperature-sensitive paralytic mutants reveal in vivo functional interactions between NSF and calcium channel proteins in synaptic transmission. Abstract presented at the 40th Annual Drosophila Research Conference, Seattle, WA.

Dellinger BB, Felling R, Ordway RW (2000) Genetic modifiers of the Drosophila NSF mutant, comatose, include a temperature-sensitive paralytic allele of the calcium channel $\alpha 1$ subunit gene, cacophony. Genetics 155:203-211.

Grigliatti TA, Hall L, Rosenbluth R, Suzuki DT (1973) Temperaturesensitive mutations in Drosophila melanogaster. XIV. A selection of immobile adults. Mol Genet 120:107-114.

Heisenberg M, Götz KG (1975) The use of mutations for the partial degradation of vision in Drosophila melanogaster. J Comp Physiol 98:217-241.

Hering S, Berjukow S, Aczél S, Timin EN (1998) $\mathrm{Ca}^{2+}$ channel block 
and inactivation: common molecular determinants. Trends Pharmacol Sci 19:439-443.

Hess EJ (1996) Migraines in mice? Cell 87:1149-1151.

Hoshi T, Zagotta WN, Aldrich RW (1991) Two types of inactivation in Shaker $\mathrm{K}^{+}$channels: effects of alterations in the carboxy-terminal region. Neuron 7:547-556.

Kawasaki F, Ordway RW (1999a) The Drosophila NSF protein, dNSF1, plays a similar role at neuromuscular and some central synapses. J Neurophysiol 82:123-130.

Kawasaki F, Ordway RW (1999b) A new model synapse preparation allows direct demonstration of a strictly presynaptic role for the Drosophila NSF protein, dNSF1. Abstract presented at the 40th Annual Drosophila Research Conference, Seattle, WA.

Kawasaki F, Mattiuz AM, Ordway RW (1998) Synaptic physiology and ultrastructure in comatose mutants define an in vivo role for NSF in neurotransmitter release. J Neurosci 18:10241-10249.

Kawasaki F, Felling R, Ordway RW (1999) A temperature-sensitive paralytic mutant defines a primary synaptic calcium channel in Drosophila. Abstract presented at the 1999 Cold Spring Harbor Meeting on Neurobiology of Drosophila, Cold Spring Harbor, NY.

McPhee JC, Ragsdale DS, Scheuer T, Catterall WA (1995) A critical role for transmembrane segment IVS6 of the sodium channel $\alpha$ subunit in fast inactivation. J Biol Chem 270:12025-12034.

Miller RJ (1997) Calcium channels prove to be a real headache. Trends Neurosci 20:189-192.

Mochida S, Sheng Z-H, Carl B, Kobayashi H, Catterall WA (1996) Inhibition of neurotransmission by peptides containing the synaptic protein interaction site of N-type $\mathrm{Ca}^{2+}$ channels. Neuron 17:781-788.

Ordway RW, Pallanck L, Ganetzky B (1994) Neurally expressed Drosophila genes encoding homologs of the NSF and SNAP secretory proteins. Proc Natl Acad Sci USA 91:5715-5719.

Pallanck L, Ordway RW, Ganetzky B (1995) A Drosophila NSF mutant. Nature 376:25.

Peixoto AA, Hall JC (1998) Analysis of temperature-sensitive mutants reveals new genes involved in the courtship song of Drosophila. Genetics 148:827-838.

Rettig J, Heinemann C, Ashery U, Sheng Z-H, Yokoyama CT, Catterall WA, Neher E (1997) Alteration of $\mathrm{Ca}^{2+}$ dependence of neurotransmitter release by disruption of $\mathrm{Ca}^{2+}$ channel/syntaxin interaction. J Neurosci 17:6647-6656.
Robitaille R, Adler EM, Charlton MP (1990) Strategic location of calcium channels at transmitter release sites of frog neuromuscular synapses. Neuron 5:773-779.

Rojas CV, Wang J, Schwartz LS, Hoffman EP, Powell BR, Brown Jr RH (1991) A Met-to-Val mutation in the skeletal muscle $\mathrm{Na}^{+}$channel $\alpha$-subunit in hyperkalaemic periodic paralysis. Nature 354:387-389.

Sheng Z-H, Westenbroek RE, Catterall WA (1998) Physical link and functional coupling of presynaptic calcium channels and the synaptic vesicle docking/fusion machinery. J Bioenerg Biomembr 30:335-345.

Siddiqi O, Benzer S (1976) Neurophysiological defects in temperaturesensitive paralytic mutants of Drosophila melanogaster. Proc Natl Acad Sci USA 73:3253-3257.

Smith LA, Wang X, Peixoto AA, Neumann EK, Hall LM, Hall JC (1996) A Drosophila calcium channel $\alpha 1$ subunit gene maps to a genetic locus associated with behavioral and visual defects. J Neurosci 16:7868-7879.

Smith LA, Peixoto AA, Kramer EM, Villella A, Hall JC (1998) Courtship and visual defects of cacophony mutants reveal functional complexity of a calcium-channel $\alpha 1$ subunit in Drosophila. Genetics 149:1407-1426.

Suzuki DT, Grigliatti T, Williamson R (1971) Temperature-sensitive mutations in Drosophila melanogaster. VII. A mutation ( para $^{\mathrm{TS}}$ ) causing reversible adult paralysis. Proc Natl Acad Sci USA 68:890-893.

von Schilcher F (1976) The behavior of cacophony, a courtship song mutant in Drosophila melanogaster. Behav Biol 17:187-196.

von Schilcher F (1977) A mutation which changes courtship song in Drosophila melanogaster. Behav Genet 7:251-259.

Westenbroek RE, Sakurai T, Elliott EM, Hell JW, Starr TV, Snutch TP, Catterall WA (1995) Immunochemical identification and subcellular distribution of the alpha 1 A subunits of brain calcium channels. J Neurosci 15:6403-6418.

Wheeler DB, Randall A, Sather WA, Tsien RW (1995) Neuronal calcium channels encoded by the $\alpha 1 \mathrm{~A}$ subunit and their contribution to excitatory synaptic transmission in the CNS. Prog Brain Res 105:65-78.

Wiser O, Trus M, Hernández A, Renström E, Barg S, Rorsman P, Atlas D (1999) The voltage sensitive Lc-type $\mathrm{Ca}^{2+}$ channel is functionally coupled to the exocytotic machinery. Proc Natl Acad Sci USA 96:248-253.

Zhang J-F, Ellinor PT, Aldrich RW, Tsien RW (1994) Molecular determinants of voltage-dependent inactivation in calcium channels. Nature 372:97-100. 